\title{
EDITORIAL
}

\section{Responding to the Call: a New JGIM Area of Emphasis for Implementation and Quality Improvement Sciences}

\author{
J Gen Intern Med 35(Suppl 2):S781-S2 \\ DOI: $10.1007 / \mathrm{s} 11606-020-06229-8$ \\ (c) Society of General Internal Medicine (This is a U.S. government work and \\ not under copyright protection in the U.S.; foreign copyright protection \\ may apply) 2020
}

Christian D. Helfrich, MPH, $P h D^{7}$ and Lucy A. Savitz, $P h D, M B A^{2}$

'Seattle-Denver Center of Innovation for Veteran-Centered and Value-Driven Care, Department of Health Services, University of Washington School of Public Health, Seattle, WA, USA; ${ }^{2}$ Health Research Kaiser Permanente Northwest Region, Center for Health Research, Kaiser Permanente School of Medicine, Oregon Health \& Science University - Portland State University School of Public Health, Portland, OR, USA.

$\mathrm{W}$ e are pleased to announce the publication of the special issue of the Journal of General Internal Medicine on implementation science (IS) and quality improvement (QI), an event which, marks the formal addition of IS/QI as an area of emphasis for JGIM. Why is this important? In the words of JGIM Editor-in-Chief Steven Asch, "We all love the research we publish in JGIM, but research without action always seems incomplete. Increasing our emphasis on research on how best to diffuse best practices and even publishing examples of improvement efforts completes that circle." The articles in this special issue represent steps in that circle from knowledge to action.

This issue comes out at a point in time when both the strengths and vulnerabilities of our healthcare system have been exposed. The current COVID-19 crisis has presented unique opportunities to study accelerated implementation and challenges in pacing the organizational learning with practice needs in real time. The COVID-19 crisis has also focused attention on systemic racism in diagnosis and treatment of illness in people of color.

It reminds us of the importance of IS/QI research in developing a better prepared, more resilient healthcare system; to be prepared to pivot to respond to emergent challenges; and conversely to remain focused on the long-term work that will help create a better healthcare system tomorrow.

The scholarly communities of IS and QI have co-evolved to address the challenge of using the systematic rigor of science to help close quality gaps. Hallmarks of this work include attention to how the change process occurs; sensitivity to context; the interplay of implementation participants with the evidence-anchored innovations being implemented; and how generalizable knowledge is adapted to specific clinical contexts to improve a specific outcome ${ }^{1,2}$. In this JGIM Special Issue, our aim was to showcase research that advances actual

Published online October 26, 2020 care delivery by applying and testing knowledge from these synergistic fields.

To achieve that aim, we sought innovative research that applied evidence across diverse delivery systems and settings. While we wanted theoretically grounded work, we favored papers that empirically illustrate the application of foundational knowledge and skills from QI and IS to improve general internal medicine, such as Rikin and colleagues' steppedwedge trial of an opt-in e-Consult program and its effect on specialty care visits ${ }^{3}$; and Keddem and colleagues' rigorous qualitative study of implementation of patient-engagement toolkits ${ }^{4}$.

We wanted to include well-developed negative findings, like Mann and colleagues' study, which used a cluster randomized design to test clinical decision support to reduce antibiotic prescribing for acute respiratory infections ${ }^{5}$. This type of disconfirming evidence is what leads us to question and revise our existing mental models, and ultimately develop a more accurate understanding of the problems we are trying to solve.

Inclusion of multi-site studies demonstrates how organizational and institutional context exert such profound influences on implementation outcomes and surface the complex effects of context in understanding how implementation varies across multiple settings. For example, Petrik and colleagues assessed implementation drivers that could explain differences among federally qualified community health centers in their success implementing FIT $^{6}$.

We wanted to include work that addressed reducing or deimplementing low-value care, such as Presti and colleagues' paper on reducing inappropriate PSA screening ${ }^{7}$. Deimplementing low-value care is an essential part of efforts to improve healthcare quality and one that has sometimes been too-little studied.

Directly addressing concerns of rigor in this research space, we sought examples of rigorous non-experimental designs, such as Coleman and colleagues' observational study of institutionalizing collaborative care for depres$\operatorname{sion}^{8}$, and Rattray and colleagues' rigorous QI project of a web-based hub for audit and feedback for improving care for transient ischemic attacks 9 .

Several selected papers aim to advance implementation science/rigorous QI methodology, such as Wagner's paper proposing how cost can better be evaluated in 
implementation studies ${ }^{10}$; Esmail and colleagues' proposed standards for conducting and reporting comparative health effectiveness for complex interventions ${ }^{11}$; and Hernandez-Diaz and colleagues' proposed methods for extracting learning-health systems lessons from AHRQ studies ${ }^{12}$. These methodology papers will help the field to continue to improve the validity and reliability of the findings we produce.

Finally, we wanted to include papers that provide high-level synthesis and wisdom on innovative, improvement efforts and to help us see both what this field has accomplished and where we can collectively advance. Kamath and colleagues' systematic review provides this type of synthesis of our knowledge for the specific issue of interventions to improve blood pressure management for patients with chronic kidney disease in primary care ${ }^{13}$. And Drs. Kilbourne, Glasgow, and Chambers provide a rich, higher-level overview of important contributions from IS with selected stories amplifying successes from the field ${ }^{14}$.

In sum, these papers illustrate how IS and QI can advance internal-medicine care delivery and ensure that the foundational knowledge generated by internalmedicine research finds its way into practice. Without the selfless dedication and thoughtful reviews of submitted manuscripts, this Special Issue would not have been possible. Service to our field is an important contributing factor that supports the overall health and completeness of our evidence base. With many competing demands including their own scientific endeavors, administrative and other work responsibilities, and an emerging global pandemic, these individuals were important contributors and we sincerely thank them.

We also wish to thank our sponsor organizations that include the Agency for Healthcare Research and Quality, Kaiser Permanente, and the Veterans Administration, as well as the JGIM senior editors. Their sponsorship made this special issue possible.

Corresponding Author: Christian D. Helfrich, MPH, PhD; SeattleDenver Center of Innovation for Veteran-Centered and Value-Driven Care, Department of Health Services, University of Washington School of Public Health, Seattle, WA, USA (e-mail: helfrich@uw.edu).

\section{REFERENCES}

1. Batalden PB, Davidoff $\mathbf{F}$. What is "quality improvement" and how can it transform healthcare? Qual Saf Health Care. 2007. https://doi.org/10. 1136/qshc.2006.022046.

2. Fisher ES, Shortell SM, Savitz LA. Implementation science: A potential catalyst for delivery system reform. JAMA J Am Med Assoc. 2016. https://doi.org/10.1001/jama.2015.17949.

3. Rikin S, Zhang C, Lipsey D, et al. Impact of an opt-in eConsult program on primary care demand for specialty visits: stepped-wedge cluster randomized implementation study. J Gen Intern Med. 2020. https:// doi.org/10.1007/s11606-020-06101-9

4. Keddem S, Agha A, Long J, Shasha B, Hausmann L, Shea J. The Gears of Knowledge Translation: Process Evaluation of the Dissemination and Implementation of a Patient Engagement Toolkit. J Gen Intern Med. 2020. https://doi.org/10.1007/s11606-020-06099-0.

5. Mann D, Hess R, McGinn T, et al. Impact of clinical decision support on antibiotic prescribing for acute respiratory infections: a cluster randomized implementation trial. J Gen Intern Med. 2020. https://doi.org/10. 1007/s11606-020-06096-3.

6. Petrik A, Green B, Schneider J, et al. Factors influencing implementation of a colorectal cancer screening improvement program in community health centers: an applied use of configurational comparative methods. J Gen Intern Med. https://doi.org/10.1007/s11606-02006186-2

7. Presti J, Alexeeff S, Horton B, Prausnitz S, Avins A. Changing Provider PSA Screening Behavior Using Best Practice Advisories: Interventional Study in a Multispecialty Group Practice. J Gen Intern Med. https://doi. org/10.1007/s11606-020-06097-2

8. Coleman $\mathbf{K}$, Dreskin $\mathbf{M}$, Hackett $\mathbf{D}$, et al. A Roadmap for Institutionalizing Collaborative Care for Depression in a Large Integrated Healthcare System. J Gen Intern Med. https://doi.org/10.1007/s11606-02006102-8

9. Rattray N, Damush T, Miech E, et al. Empowering implementation teams with a learning health system approach: leveraging data to improve quality of care for transient ischemic attack. J Gen Intern Med. https://doi.org/10.1007/s11606-020-06160-y

10. Wagner T. Rethinking How We Measure Costs in Implementation Research. J Gen Intern Med. https://doi.org/10.1007/s11606-02006104-6

11. Esmail L, Barasky R, Mittman B, Hickam D. Improving Comparative Effectiveness Research of Complex Health Interventions: Standards from the Patient-Centered Outcomes Research Institute (PCORI). J Gen Intern Med. https://doi.org/10.1007/s11606-020-06093-6

12. Hernandez-Diaz A, Roman Y, White C. Developing Criteria and Associated Instructions for Consistent and Useful Quality Improvement Study Data Extraction for Health Systems. J Gen Intern Med. https:// doi.org/10.1007/s11606-020-06098-1

13. Kamath C, Dobler C, McCoy R, et al. Improving blood pressure management in primary care patients with chronic kidney disease: A systematic review of interventions and implementation strategies. J Gen Intern Med. https://doi.org/10.1007/s11606-020-06103-7

14. Kilbourne A, Glasgow $\mathbf{R}$, Chambers $\mathbf{D}$. What Can Implementation Science Do for You? Key Success Stories from the Field. J Gen Intern Med. https://doi.org/10.1007/s11606-020-06174-6

Publisher's Note: Springer Nature remains neutral with regard to jurisdictional claims in published maps and institutional affiliations. 